\title{
PASSADO-PRESENTE NA MEMÓRIA DE TRABALHADORES: IMAGEM E PRESENÇA NO FILME ETNOGRÁFICO
}

\author{
Ana Lúcia Marques Camargo Ferraz ${ }^{1}$
}

A produção e circulação de imagens na prática da pesquisa etnográfica dá a ver as relações entre imagem e tempo, especificamente evidencia o fenômeno da cristalização de experiências e a possibilidade de sua atualização no presente. Trabalhando com o vídeo etnográfico entre grupos de trabalhadores urbanos no Brasil, acompanhei suas dinâmicas através da pesquisa de longa duração. Nessas experiências, pude atuar na produção de narrativas mobilizando diversos expedientes: a gravação de relatos de histórias de vida ou de trajetórias profissionais, a visualização de registros em vídeo produzidos pelos próprios grupos, a visualização de outros filmes com o fim de abrir diálogos, e o retorno de edições em vídeo de materiais gravados com o grupo, tempos antes. Pela rememoração, no diálogo, na utilização de imagens em movimento, como meio que aciona uma relação com outros tempos, atuamos na atualização de experiências passadas. A rememoração de instantes e experiências confere o sentido a partir do qual se retoma a experiência vivida e se dá a emergência de afetos e aprendizagem.

Essas reflexões apresentam uma contribuição aos debates sobre as relações entre imagem e memória, tanto quanto visam aprofundar a reflexão metodológica sobre o trabalho com o filme na antropologia, os recursos de que nos valemos na pesquisa etnográfica quando entramos em contato com imagens produzidas em outros tempos. Procedo então a uma discussão teórica, retomando o debate em torno de uma "epistemologia da imagem" (Samain, 2007) de que carecemos para dar sequência metodológica a um acúmulo etnográfico fruto de processos de pesquisa mediados pela produção de vídeo.

Trabalho na realização de etnografias mediadas pelo vídeo entre grupos urbanos, acompanhando suas dinâmicas. Por meio da pesquisa de longa duração observo o

\footnotetext{
${ }^{1}$ Universidade Federal Fluminense, Brasil.
} 
fenômeno da rememoração, produtor de avaliações capazes de explicar situações presentes ou justificar disposições atuais, a experiência vivida parece ser formadora de valores e práticas. Desenvolvo reflexões a partir de algumas experiências de pesquisa: o diálogo com grupos de trabalhadores da região metropolitana de São Paulo, mantido entre 1995 e 2005, o diálogo mantido com artistas circenses, entre 2005 e 2010 e suas elaborações metodológicas, como casos em que o trabalho com o filme assume caminhos particulares nas articulações entre imagem, memória e presença.

Trata-se de refletir acerca da mobilização de imagens no agora da pesquisa etnográfica e acerca de sua potencialidade de presentificação de outros tempos, que desencadeia processos de rememoração abrindo espaços em que visualizamos uma noção de projeto. Uma antropologia que lida com as potências da noção de duração (Bergson, 1934), que implica uma concepção de tempo como aberto, encontra não apenas as formas sociais estruturadas, mas também, projeções, desejos, possibilidades vislumbradas em instantes em que o tempo estabelece pontes, momentos de narrar o vivido inaugurados pela pesquisa. Ao dar atenção à dimensão da atualização operada pela imagem persigo o debate em torno da questão da duração, numa linha que se constituiu a partir de meu diálogo com Míriam Lifchitz Moreira Leite, que articula leituras de Bergson, (1990 [1897]); Bachelard, (1994 [1950]) e Deleuze, (1999 [1966]).

A memória atualiza imagens, formas que se fixam em instantes do tempo. A cristalização da materialidade do mundo possibilitada pelos meios de produzir imagem que estão dados em nossa sociedade, abre essa passagem entre tempos e nos coloca questões que gostaria de aprofundar. Para além do trabalho de impregnação da luz sobre superfície sensível, ou das virtudes descritivas dos meios audiovisuais, refiro-me às imagens postas em movimento no diálogo etnográfico, que são constantemente produzidas, postas em circulação, recebidas. Refiro-me ao trabalho etnográfico de estabelecer relações que o vídeo etnográfico potencializa na ação do antropólogo de produzir conhecimento, quando abre, em campo, a reflexão sobre as formas sociais e sobre o seu movimento de deixarem de ser e de se tornarem outras, que se percebe no estudo da vida que dura e se torna outra, devém, no tempo.

De um modo particular, o filme torna possível a presença de um outro presente, no agora de sua exibição. No trabalho que o filme faz, o passado, que é presente e está vivo, mantém relações com o atual. Como afirma Benjamin (1994: 224), “o passado só 
se deixa fixar, como imagem que relampeja irreversivelmente, no momento em que é reconhecido", passado que é presente porque não resolvido, aberto. Tais situações de lembrar são seguidas de um distanciamento produzido na percepção sobre o que já não é, o que deixou de ser. Nesses instantes o tempo opera um choque. Poderíamos aqui desenvolver uma antropologia do trauma, aquela que lida com narrativas e o seu pathos que emerge quando se vive situações que põem em cheque a ordem estruturada. Produzimos narrativas etnográficas de processos de "acomodamento do trauma no processo memória/esquecimento", vão dizer Eckert e Rocha (2009). Narrando tais experiências os homens e mulheres que encontro em campo atualizam e reelaboram o vivido na criação de uma história, em situação de pesquisa. Seria então necessário concebermos o trabalho etnográfico de nomear as "modernas sociedades complexas como experiência diegética” (Eckert e Rocha, 2009: 140).

\section{Passado-presente na memória de trabalhadores}

Retomo, então, instantes da interação em campo em pesquisas por mim realizadas. Durante a década de 90, num momento de crise do emprego e desindustrialização na região metropolitana de São Paulo, Brasil, acompanho grupos de trabalhadores que produzem relatos de experiências vividas no trabalho, num instante em que as condições de continuidade de sua posição não estavam dadas. Nesse contexto, o sentido do trabalho na formação do homem aparece ao lado de narrativas sobre o processo de intensificação do ritmo de trabalho e do controle, sob formas individuais de responsabilização e cobrança por produtividade. Frente às demissões massivas na indústria, num momento de perigo, os relatos destacam as relações no interior do grupo, os aprendizados comuns, retomam lembranças dos momentos de fazer parte de um coletivo, a aprendizagem que se faz no tempo.

Opero aqui por fragmentos, como faz Benjamin. O jovem trabalhador que herda de seu pai seu posto de trabalho na Ford, montadora de automóveis em São Bernardo do Campo, região industrial de São Paulo, narra, em 1997, suas reminiscências: "Em 1986 perdi quase todos os companheiros de seção. Desde que entrei, em 84, não tinha me deparado com isso. Em 86, virou o maior chicote lá dentro. Me deparei também com o fechamento da fábrica de motores." 
Em 1997, o jovem trabalhador lembra do outro tempo em que viveu experiência semelhante. Com a saída da Comissão de Fábrica cresce o "chicote", a categoria aponta a intensa aceleração do ritmo em que trabalha o corpo do trabalhador. Mas em 1998, o "facão" se impõe. Essas categorias "chicote", "facão" retomam experiências de trabalho no campo que herdam outras relações.

A fala do trabalhador é produzida no contexto em que a Ford demitira dois mil e oitocentos trabalhadores. Nessa situação, o valor de ser parte de um coletivo, membro do grupo, aparece com ênfase nas falas produzidas. Neste momento edito um vídeo a partir do material gravado durante os meses de mobilização contra as duas mil e oitocentas demissões na Ford. A edição acompanha o cotidiano do movimento, reconstruindo o evento e seu ritmo.

O vídeo Feliz ano novo, véio! (Ferraz, 1999), http://vimeo.com/user7736951/felizanonovoveio que registra as mobilizações e as narrativas de experiências produzidas naquele instante, foi apropriado e reproduzido pelos trabalhadores e circulava entre eles, reforçando a mobilização. Em suas assembleias ou nas reuniões domésticas que fizeram nos bairros, pelo tempo longo em que conseguiram resistir à demissão, a visualização do vídeo recuperava a potência da mobilização, o sentido do fazer parte, de uma sociabilidade que funda um modo de ser, uma ética formada a partir da experiência da migração e da integração à vida na metrópole pelo trabalho.

Nesse contexto, ouvi cineastas que acompanharam o primeiro momento de tomada do Sindicato dos Metalúrgicos de São Bernardo do Campo, no ABC paulista pelos movimentos grevistas no final da ditadura militar. Adrian Cooper, que fez a fotografia do filme $A B C$ da greve (1979/1990), dirigido por Leon Hirszman, comenta o trabalho do cameraman na produção de imagens acompanhando os movimentos grevistas que marcam a virada dos anos 80 e põem em cheque a ditadura militar no Brasil.

Eu lembro da volta do Sindicato que me toca muito pelo orgulho das pessoas, o prazer que eles tinham. Era uma vitória, dentro de uma derrota fantástica, era uma vitória muito pequena, aparentemente, dentro de uma derrota muito grande, os operários voltaram a trabalhar de cabeça baixa, perderam tudo. Agora ganharam uma coisa que nunca o governo e os empresários perceberam o quanto era importante aquela decisão do Lula de retomar o Sindicato. (...) "Eu não sei se hoje as pessoas teriam a mesma relação com o seu sindicato, era uma coisa que vai além 
da greve em si, era uma coisa que tem muito a ver com o prazer de sua identidade." Adrian Cooper, em entrevista por mim realizada em 1999.

Como Bachelard sugere, estudei "os fenômenos temporais cada qual segundo um ritmo apropriado, um ponto de vista particular" (1994: 7). Pois bem, ali, em 1998, na relação com os trabalhadores das montadoras de automóveis, apreendi o instante de transição entre dois tempos, uma virada. O vídeo Feliz ano novo, véio! reconstrói um instante, um intervalo entre duas durações. $\mathrm{O}$ momento em que a representação sindical consolidada desde o final da década de 70 abre mão dos interesses dos trabalhadores em função dos rearranjos empresariais por acréscimo de produtividade com redução de trabalho, chantageada pela pressão da desindustrialização. Pasmo, desterro, vertigem. A questão vivida pelos trabalhadores é: 'que fazer agora, fora do meu grupo, da atividade em que me formei como pessoa?'.

A memória da organização dos trabalhadores nos locais de trabalho, de seus direitos adquiridos com a mobilização coletiva, é fortemente mobilizada neste instante em que a continuidade do grupo está em questão, mas a compreensão de um processo de institucionalização das organizações de trabalhadores vai configurar uma nova duração, um novo instante, distinto qualitativamente do anterior. Temos assim, no conceito de duração, uma categoria que nos possibilita simultaneamente compreender os processos que são subjetivamente vividos e narrados, e, objetivamente constituídos, impondo-se para todo o grupo, caracterizando um novo instante no tempo, com qualidades distintas do momento anterior.

É nesse instante, que abre uma fissura no tempo, que os interlocutores da pesquisa narram suas experiências. No momento que o perigo de deixar de ser se coloca, Betão, líder sindical e membro da Comissão de Fábrica da montadora de automóveis, rememora:

Em 1986, a gente tinha nova eleição da Comissão de Fábrica. A fábrica chamou para hora extra e nós fomos fazer piquete. A fábrica demitiu um companheiro que tinha trinta dias de mandato. Parou! Mas, dentro da Comissão teve divergências. Achávamos que não devia parar a fábrica, a gente sabia que a peãozada não queria parar. Parou. Não estava legal, o peão sentiu que o movimento não era dele, era mais da direção. A comissão aumentou de 14 para 26. E a gente parou a fábrica e ficou parado. Greve, greve!

O Jair (Meneguelli) me chamou aqui no Sindicato: 'Betão dá para você vir aqui para o sindicato?’. O pessoal achou que não deveria vir, mas viemos, eu e mais seis ou 
sete da Comissão. Jair (Meneguelli): 'O Tuma ligou dizendo que vai ter problema na Ford. Tem que produzir'. Chegou na fábrica, não entramos mais, estava cheio de polícia cercando a fábrica. Aí os companheiros questionaram: 'Porque saíram da fábrica? Não era para ter saído'. Saímos, não entramos mais. A gente ficou de fora. Os companheiros questionaram... A fábrica fez triagem. Aí, a fábrica foi esvaziando o movimento. Achamos que devia terminar o movimento. Vinte e seis companheiros da Comissão de Fábrica demitidos! Entrou todo mundo chorando para trabalhar. Todo mundo chorando. Chegamos aqui no sindicato, fomos para uma sala lá em cima, choramos, choramos... Mas choramos, menina! Choramos todo mundo!

Naquela época já tinha briga na Comissão por poder. Tinha muita gente boa e tinha divergência. Desde 82, só conquista, aí, chegou 86, demitiu e não tinha mais jeito. Aí a fábrica começou a adotar uma nova política, uma política diferente. Nós fomos processados. Sete para a polícia federal. O processo terminou agora em 94, em 95 arquivaram o processo. Mas a greve deu muito o que falar. Fizemos greves muito diferentes: o pessoal fazia desenho, muito bonito, cada um queria fazer um desenho diferente... Teve um momento em que a Ford tirou toda a gerência da área. Aí nós fomos para as áreas, ligamos as máquinas... Esses movimentos vão politizando demais o pessoal(...). Betão, membro da Comissão de Fábrica, em entrevista por mim realizada, em 1999.

Na narrativa de Betão o tempo se imobiliza. Ele segue cronológico: de 80 a 86 e retorna para o seu início. É no momento em que se fala de "transição democrática", em 1986, que Betão vive a experiência do exílio. O trabalhador teve o seu direito ao trabalho de organização dos trabalhadores caçado. Em sua narrativa, há uma elipse entre 86 e 94, o tempo vivido fora da fábrica. O primeiro momento a que se refere o trabalhador é aquele em que, no Sindicato, "tinha gente boa e tinha espaço para as divergências".

Quando se funda um partido o foco da atuação deixa a disputa sobre o ritmo em que trabalha o corpo. Nessa concepção o Estado, destituído de conteúdo, é um lugar a se ocupar. Abrindo "lençóis de passado", Betão rememora instantes delicados na institucionalização da representação dos trabalhadores. Ao elogiar o espaço da divergência, tece uma crítica velada às formas da política sindical atual, que cria organizações com o fim do controle sobre os trabalhadores. Posicionando-se, afasta-se do presente que já é passado.

As formas institucionais que se fixam abandonam o movimento, e a disputa se torna encenação. Na compreensão do político como algo externo ao cotidiano da produção, a representação sindical é mais ausência que presença. Frente ao desemprego exercendo seus efeitos dentro e fora dos locais de trabalho, cresce a heterogeneidade de classe e, com ela, processos de diferenciação da classe trabalhadora. A partir dessa etnografia, e retomando o contato com os indivíduos que viveram a experiência do lay 
off, reencontro pessoas em diversas situações. A geração de Betão já não está mais na fábrica e os mais jovens não compartilham a experiência de formação dos mais velhos.

Os trabalhadores que foram dispensados depois do lay off $f^{2}$ esperavam ser reincorporados à fábrica. José Carlos dedica-se a estudar novas possibilidades de atuação, estuda fotografia e faz teatro. A avaliação que ele fez da experiência foi dura, sente-se traído pelos antigos companheiros de trabalho que se institucionalizaram como representantes. De sua casa vê os muros da fábrica, sente-se injustiçado. Sidnei Puca, outro trabalhador altamente qualificado, foi reincorporado à fábrica e quando retorna passa a trabalhar como segurança patrimonial, a despeito de toda a sua formação como técnico em mecatrônica. Estes são processos de desqualificação de toda uma população. Guitarrinha segue desempregado; fora da fábrica passa a beber e termina seu casamento. Sem trabalho, desestrutura-se pessoalmente.

O momento de rever o vídeo para esses trabalhadores foi produtor de uma crítica perplexa, em que a materialidade da vida se apresenta frente à imagem do passado que ainda nem é tão distante. O tempo, assim como as instituições, parece ignorar as biografias. Os processos sociais de intensificação da heterogeneidade da classe trabalhadora tomados na longa duração e a partir da dialogia, proporcionam encontros entre passados presentes, situações produtoras de novas compreensões.

Apesar da sua tendência a imitar a percepção se realizando, nota Bergson, nossa lembrança "permanece ligada ao passado por suas raízes profundas, e se, uma vez realizada, ela não se ressente de sua virtualidade original, se ela não fosse, ao mesmo tempo, um estado presente, algo que se corta sobre o presente, nós não a reconheceríamos jamais como uma lembrança”. É a partir de um presente que já é passado que falam os trabalhadores. Mas, o passado coexiste latente. O que nós tenhamos uma vez visto, entendido, provado, aprendido, não é definitivamente perdido, mas sobrevive como virtualidade.

Por outro lado, notamos nas possibilidades desenhadas pelos grupos a presença da percepção marcada pela experiência passada. Ao discutir as noções de protensão e retenção, Schutz (1979) discute a persistência das formas sociais no fenômeno da memória: "a lembrança de uma experiência do mundo exterior é relativamente nítida,

\footnotetext{
${ }^{2}$ O lay off foi a forma contratada entre representação sindical, empresa e governo, incentivando a rescisão do contrato de trabalho com subsídio publico por algum tempo. Esta foi a forma implementada no caso das 2800 demissões na Ford de São Bernardo do Campo, em 1999.
} 
uma sequência de acontecimentos externos, um movimento talvez, pode ser lembrado numa reprodução, isto é, escolhendo-se arbitrariamente determinados pontos da duração. (...) É no interior do tempo, ou na durée, que nossas experiências atuais são ligadas ao passado, por meio de lembranças e retenções, e ao futuro, por meio de protensões e antecipações. (...) É o conhecimento à mão que serve de código de interpretação da experiência atual em curso. Essa referência a atos já vivenciados pressupõe memória, e todas as suas funções, tais como lembrança, retenção, reconhecimento (Schutz, 1979: 64).

Mas, na pesquisa etnográfica de longa duração entre grupos de trabalhadores, quando mobilizamos imagens de outros tempos, propondo momentos de lembrar, no diálogo com os sujeitos que acompanhamos inseridos em processos sociais e ciosos de suas experiências vividas, encontramos outros aspectos da memória. Quando colocamos imagens em circulação, atualizando outros tempos, os comentários de nossos interlocutores revisam o instante passado, no entanto as observações feitas também se referem a imagens de porvir, desejos, linhas em esboços, dando a ver o modo como o tempo atua também na sua dimensão de aberto e indeterminado.

Exemplifico, narrando a experiência de acompanhar um grupo de trabalhadores em uma indústria metalúrgica em estado falimentar. No momento em que esses trabalhadores constroem o projeto de seguir produzindo sob autogestão, revimos imagens produzidas em outra época da história do grupo (Ferraz, 2009: 165). Nessa experiência, realizada no início dos anos 2000, acompanho processos em que grupos de trabalhadores pleiteiam o direito de seguirem trabalhando mesmo depois das empresas empregadoras abrirem falência. Dissociando as noções de trabalho e emprego, os trabalhadores reafirmam a importância do coletivo com o qual eles se constituíram como homo faber. Visualizar outros tempos se configura como momento catártico de rememoração em que se redefine uma perspectiva de continuidade comum e justificada, fortalecida pelos sentidos atualizados da experiência coletiva.

Em campo, compartilhando a produção de alguma compreensão, num instante de absoluta transfiguração das formas sociais, de desterritorialização, o que faz experimentar a abertura do tempo e uma noção de devir, revimos imagens reunidas pelo grupo, atualizando os instantes em que, com a ausência do patrão, o grupo de trabalhadores se mantém como coletivo, reorganizando novas atividades produtivas. 
A conexão entre instantes diferentes do tempo, no contato com materiais produzidos dez anos antes, quando as pessoas reveem-se transformadas e notam a permanência do grupo, é importante na elaboração de um projeto comum. A memória como atualização de tempo, como presentificação, tem virtudes catárticas, extáticas, diria Eisenstein, transformativas.

Um debate acerca do "presente etnográfico" aparece na disciplina como modo de narrar predominante nas monografias etnográficas, por meio dessa forma articulamos narrativas de um coletivo - a explicação de ações presentes, a narrativa do que se coloca como tradição/passado institucionalizado, nas formas sociais cristalizadas. James Clifford (2008: 29) destaca o modo como a etnografia clássica caracteriza-se por ser sincrônica, "produto de uma atividade de curta duração". Narramos as situações da pesquisa etnográfica e as vozes de nossos interlocutores no presente, mas, este instante é recortado, tecido pela presença de outras durações. Trabalhar com o filme etnográfico, na pesquisa de longa duração (Burawoy, 2003), nos coloca frente à dimensão da memória, da presença concreta da experiência vivida. Dessa forma, o presente etnográfico aparece em sua densidade de composto de $n$ dimensões do tempo, passadopresente e devir, em sua dimensão de indeterminado, intenso, aberto.

Aproximar memória e presença é possível nessa chave de leitura, já que na prática das filmagens, fixamos instantes e as narrativas sobre eles, estabelecendo pontes. As experiências realizadas com o vídeo permitem afirmar a contração do real operada na memória, no modo como se seleciona, se recuperam elementos. Com o vídeo etnográfico, produzimos etnografias da duração, do tempo qualitativamente vivido, percebido, concebido.

Flaherty, por exemplo, em $O$ homem de Aran, fez encenar os costumes e práticas narrados por seus interlocutores, dados presentes na memória dos habitantes de Aran. Inventando um homem típico, encenado pelos habitantes, a partir de relatos colhidos, das histórias ouvidas, da observação da vida local e do estabelecimento de parcerias com sujeitos concretos que atuam para a câmera, produz filmes que influenciam o campo do filme etnográfico, marcando as abordagens que vão se desenvolver mais tarde (Heider, 1995; Rouch, 1978). Atuar a partir de uma configuração do imaginário que se dá na relação produtora que é a pesquisa. 
Mais que isso, interessa aqui transcender as possibilidades representativas do meio fílmico e mobilizar as virtudes evocativas do modo de operação do filme etnográfico (Crawford 1992: 78; MacDougall 1994b: 267). Dar a ver os trabalhos do tempo no modo como o filme produz performances e, no modo como, na esfera da circulação das imagens, atualizamos tempo. "Aqui, o filme poderia ser discutido como ultrapassando a representação e confrontando o espectador uma vez mais com o estímulo primário da experiência física" (MacDougall, 1994b: 267). A materialidade do mundo, a presença dos corpos, a vibração dos gestos, o ritmo do mundo e das relações, cristalizados na película nos devolvem a experiência. No filme e na experiência de sua recepção o saber mobilizado pelo contato etnográfico circula socialmente.

“Memórias não podem simplesmente ser 'inscritas' pela linguagem ou pelas imagens; elas são 'habitadas' pelos nossos corpos no espaço e no tempo" (Grossman, 2010). O filme etnográfico de Grossman convida o espectador a habitar, mais que meramente assistir, as memórias na tela. Como a autora diz: "O filme pretende evocar a 'imaginação sensual' do espectador (Healy 2003: 223 apud Grossman, 2010), para despertar emoções e percepções próximas às dos verdadeiros processos de rememoração. Abordar o tema de tal modo retoma uma interpretação bergsoniana da memória não como fisicamente alojada na matéria, mas como movimento constante, ainda que descontínuo, tecido na sensação incorporada e nas experiências da duração do tempo" (Grossman, 2010: 170).

Dimensões sensíveis do conhecimento, como sublinha a obra de Pink (2001; 2006), colocam a câmera como ferramenta de pesquisa por excelência, mais que simples modo de registro prévio à teorização. Memória é fenômeno intangível, mobiliza espaços evocativos de sentimento. Imagem e memória compartilham o trabalho entre presença e ausência, recuperando, a partir do visível, o invisível do mundo do afeto. Porque "o olho não é somente o órgão que vê, mas é, também, o que chora", cito Veena (Das, 2012: 354). Um corporeal turn na antropologia é afirmado por MacDougall (2006) quando discute seus New principles of Visual Anthropology, ressaltando os aspectos performáticos mobilizados pelos sujeitos em campo, apontando as áreas da antropologia e da experiência social com as quais o filme tem afinidade: o topográfico, o temporal, o corporal, o pessoal" (MacDougall, 2007: 271). 


\section{Múltiplas interpretações de Bergson}

Sublinho o elemento da percepção do tempo, no modo como ela se coloca em um ponto específico de nosso pensamento. O tempo não é mais pensado de modo abstrato, ele está vinculado a uma reflexão sobre a matéria (Bachelard, 1994), o tempo é concreto. Retomar as teses de Bergson coloca-nos em contato com os temas da experiência e do afeto. Contemporâneo e colega de Durkheim, na École Normale Supérieure, Bergson disputa e polemiza com os chamados neo-kantianos. Trata-se de uma paisagem intelectual que vive uma mudança "das certezas do mecanismo à ansiedade da indeterminação" (Guerlac, 2006: 17), ou, como afirma Bachelard, temos aqui uma ruptura epistemológica. Bergson oferece-nos uma nova maneira de pensar. "Perceber consiste em condensar períodos enormes de uma existência infinitamente diluída em alguns momentos mais diferenciados de uma vida mais intensa, e em resumir assim uma história muito longa. Perceber significa imobilizar”, dirá Bergson (2006: 88).

Em Durkheim, as representações sociais são empiricamente definidas. O tempo é social, ele não é uma categoria a priori à experiência. Desde a fundação das ciências sociais temos o tempo como elemento experimentado, percebido, concebido de modo particular. Partindo da oposição indivíduo/sociedade, Durkheim reafirma sua teoria das representações coletivas, a partir do argumento da efervescência coletiva em As formas elementares da vida religiosa, que tem um papel relativizador: o tempo é socialmente definido, o ideal social constitui "o real" (Pinheiro Filho, 1996: 78). Assim, a ciência social tem como limite o dado.

$\mathrm{O}$ argumento de Bergson é distinto. Ao apreender relações subjetivas com o tempo, nos aproxima da compreensão do modo como ele é percebido. Conceber intervalos, cortes, durações, dotadas de qualidades particulares aproxima-nos de uma abordagem em que não cabe mais opor sincronia a diacronia. Assim, podemos aprofundar compreensões, esculpir a experiência. No estudo das relações entre matéria e memória, notamos presenças mais que representações. Mas, no campo dos debates sobre a noção de duração, parece haver diferentes interpretações da obra de Bergson. Uma delas sublinha o elemento da "continuidade", na afirmação de um tempo que, embora recortado por durações distintas, se mantém enquanto fluxo. 
A tese da continuidade foi discutida e criticada por Bachelard, em Esboço de ritmanálise (1994); para o autor, o tempo vibra diferentemente. Ele defende que a duração é feita de ritmos, de "sistemas de instantes", o autor diferencia-se de Bergson sublinhando o caráter fragmentário, interrompido, desordenado do tempo. "Do bergsonismo aceitamos quase tudo, exceto a continuidade", diz Bachelard (1994: 16). A duração, ou melhor, a continuidade do tempo deve ser construída pelo discurso, a objetivação da experiência é uma elaboração que se tece a partir de descontinuidades.

Deleuze sublinha outros aspectos da obra de Bergson, destaca a noção de duração como tempo recortado, que se diferencia qualitativamente, quando atualizado. Porque a memória opera como lembrança referida a um passado, mas também como contração dirigida a um futuro (Deleuze, 1999: 45). O passado já não é mais, mas ele age. A 'lembrança pura' é virtual, contida no tempo, mas, o passado é contemporâneo do presente que ele foi. Passado e presente designam dois elementos que coexistem como imagem. "Bergson falava da imagem como um termo mediador 'que é quase matéria, à medida que se deixa ver, e quase espírito à medida que não se deixa mais tocar", vai dizer Maresca (1996) um sociólogo francês que trabalha com fotografia em suas investigações.

As experiências que tenho desenvolvido com o filme etnográfico encontram no conceito de duração uma categoria importante. Mas, nesse debate parece haver distintas interpretações da obra de Bergson. Alyssa Grossman (2010), a partir da prática de realização de filmes etnográficos, destaca o lugar da lembrança que opera no registro do descontínuo, atualizando sensações incorporadas. A duração narrada pelos sujeitos com os quais interagimos em campo é o material, o caminho para a compreensão da experiência da pesquisa mediada pelo filme etnográfico. É por entender como fundamental o trabalho do filme etnográfico na cristalização de experiências e narrativas que busco realizar "etnografias da duração" (Eckert e Rocha, 2005). Fazer pesquisa etnográfica com a mediação da imagem possibilita-nos construir novas abordagens sobre a vida social, acompanhar os processos vividos pelos sujeitos que estudamos, narrados em sua dimensão vibratória. Dar a ver concepções e práticas, estabelecer relações, atualizar gestos, expressões, potências.

A partir desses caminhos, podemos interromper o percurso para sistematizar alguma aprendizagem, sublinhar aspectos, a partir da prática de produção de filmes 
etnográficos e do contato com debates nesse campo. No estudo de situações de transição, conflito, transformação, metamorfose, como foi o caso nas etnografias dos grupos de trabalhadores que acompanhei, imagens do passado dirigem-se ao presente projetando futuros possíveis. Na Obra das Passagens, Benjamin chega a citar Bergson: “Ao final de Matière et Mémoire, Bergson desenvolve a ideia de que a percepção é uma função do tempo. Poder-se-ia dizer que, se vivêssemos segundo um outro ritmo - mais serenos diante de certas coisas, mais rápidos diante de outras -, não existiria para nós nada 'duradouro', mas tudo se desenrolaria diante de nossos olhos, tudo viria de encontro a nós" (Benjamin, 2007: 239). Nesse sonho de calmaria que não vivemos, a memória relampeja em momentos de perigo, diria Benjamin, em suas Teses sobre o conceito de história.

A reminiscência é referida ao presente, é relativa à situação contemporânea. Ou, com Bergson: "De modo geral, de direito, o passado só retorna à consciência na medida em que possa ajudar a compreender o presente e a prever o porvir: é um batedor da ação. Tomamos o caminho errado quando estudamos as funções de representação em estado isolado, como se elas fossem em si mesmas seu próprio fim, como se fôssemos puros espíritos, ocupados em ver passar imagens e idéias" (Bergson, 2006: 62). É preciso apontar a relação entre "o memorizado e seu lugar de emergência" (DidiHuberman,1998: 176), compreendendo a relação entre a lembrança e o instante em que ela emerge, compreender o que é o agora em que a memória atualiza outras durações.

A percepção presente se nutre da lembrança do passado, ela é constituinte, embora seja ressignificada a cada instante. Observar o tempo, tal como percebido, tal como narrado nos aproxima da experiência vivida. A imagem, ao cristalizar as formas do tempo, atualiza o passado, circulando socialmente presentifica as formas sociais, experiências vividas, relações. Essas dimensões foram até aqui discutidas. Gostaria ainda de refletir aprofundando um outro ponto. A imagem - ao atualizar outros tempos - opera a catarse, aproximando dimensões significativas das experiências vividas.

\section{Ver o tempo, estranhar o vivido: catarse e distanciamento}

Mas, foi na pesquisa com famílias circenses que dão vida à tradição do circoteatro, que uma outra dimensão do trabalho com a imagem se apresentou. A pesquisa 
em torno das linguagens desenvolvidas pelo circo encontra as relações familiares como tema da dramaturgia. Aqui, a investigação sobre o trabalho apareceu como o trabalho do ator. Com atores e atrizes que dão vida à tradição do circo-teatro, selecionamos os tipos da comédia de costumes para tematizar o drama vivido nas relações no interior da família-empresa, que é o circo. Criando personagens, opera-se o dispositivo de distanciar-se da própria vida, podendo vê-la diferentemente.

A noção de "etnoficção" parte aqui da referência à prática de produção de fábulas em campo, numa produção compartilhada de saberes com o grupo estudado, como realizou Jean Rouch em seu cinema antropológico. A experiência de construção de personagens resultou na elaboração de um método de trabalho que parte da elaboração do duplo, a máscara dramática, para fazer emergir o imaginário.

A reflexão sobre o teatro aplicado à pesquisa etnográfica tem se desenvolvido recentemente no trabalho de antropólogos que produzem filmes etnográficos a partir da referência à obra de Rouch. Sjöberg (2008), tem discutido o recurso à "improvisação projetiva" na pesquisa antropológica. Em seu trabalho, propõe a possibilidade do teatro aplicado à etnografia. Na atuação improvisada recorre-se à projeção de aspectos das vidas e emoções dos participantes através da ficção. Os sujeitos constroem personagens para reviverem situações, memórias de abuso (Sjöberg, 2008). Torna-se possível compreender como suas próprias identidades se relacionam com os personagens, ver a projeção. O papel é utilizado como referência e fórum de discussão.

Temos aqui casos de dividuação em que o sujeito que assume um "outro" experimenta relações virtuais com novas possibilidades de vida. Assim, pode reconhecer, desde outros pontos de vista, suas experiências. Presentificar estas vozes, mais que representá-las, é a chave que o jogo fornece. O processo de identificação atorpersonagem possibilita uma catarse real que se dá no intervalo criado pela ficção. Ficção verdadeira que produz um conhecimento sobre a experiência desde novas perspectivas. A prática antropológica na construção desse tipo de abordagem fez sua história no campo do filme etnográfico. Os debates acerca da criação de personas na obra de Jean Rouch encontram um campo múltiplo de realizações de tais práticas. O filme na pesquisa etnográfica é produto de múltiplas interações, ele só se constrói na relação. O espaço entre o videomaker e o personagem de si mesmo é lugar de constituição de um novo real. "Eu quero ver - às vezes longamente - os espaços entre o 
filmmaker e o sujeito: de imaginário e linguagem, de memória e sentimento. Estes são espaços carregados de ambiguidade, mas não são eles inclusive espaços em que a consciência é criada?” (MacDougall, 1998: 25), tradução da autora. Esse espaço, a que se refere MacDougall, a partir de sua longa trajetória na produção de filmes etnográficos, é o espaço da reflexão sobre a ordem dada.

Estamos no terreno de uma visualidade patética, que nos dá a ver a vida com seu pathos, a vida como drama. No decorrer desse processo, chegamos ao recurso do jogo de construção de personagens para dar conta de lidar com a esfera do realmente imaginado, do verdadeiramente desejado, que produz pulsões, emoções, motivações concretas. "O virtual não tem que realizar-se, mas sim atualizar-se; as regras da atualização já não são a semelhança e a limitação, mas a diferença ou a divergência e a criação" (Deleuze, 1999: 78). O que é primeiro no processo de atualização é a diferença - a diferença entre o virtual de que se parte e os atuais aos quais se chega, e também a diferença entre as linhas complementares segundo as quais a atualização se faz. Em resumo, é próprio da virtualidade existir de tal modo que ela se atualize ao diferenciarse e que seja forçada a atualizar-se, a criar linhas de diferenciação para atualizar-se", diz Deleuze (1999: 79). Atualização é criação.

No jogo lúdico que permite ver um outro de mim, o trauma é percebido, liberado ou corrigido pelo método catártico. "Temos necessidade de um método catártico mais frequente, mais flexível, a ritmanálise", diz Bachelard (1994: 128). Menos moral do que vibratória, a ritmanálise propõe-se como compreensão das presenças, de qualidades particulares, em durações específicas, recortadas para análise porque qualitativamente distintas. Notando o trabalho do tempo, o trabalho da memória e o trabalho sobre a memória que o agora realiza, essa dobra que converge, aproxima e diferencia, recria um novo presente ao esboçar futuro.

O trabalho com o filme etnográfico, por sua capacidade de produzir "cortes móveis do tempo", abriga esta potencialidade: a de condensar experiências, atualizandoas. Pondo-as em circulação, condensamos sínteses capazes de fazer vislumbrar pretensões de futuro. Assim temos não somente uma antropologia das formas estruturadas, capaz de compreender os meandros da reprodução social, mas também, e sobretudo, visualizamos esboços de projetos, ensaios silenciosos dos sujeitos que acompanhamos que criam imagens de devir. 
Referi-me aqui ao estudo do drama vivido por trabalhadores da região metropolitana de São Paulo em contexto de desindustrialização, nos anos 90, do qual extraí uma crítica às formas da representação tal como instituída. Naquele instante, produzi vídeos e os coloquei em circulação. Na pesquisa que realizei com a tradição popular do circo-teatro, experimentei a dimensão do produzir-se como imagem, criar um duplo, o personagem, como forma de construir a boa distância, um espaço para poder ver-se, nomear a própria experiência. Instaurando uma subjuntividade, o "como se fosse" outro.

Em ambos os casos, há uma função do tempo operada pela imagem. Essa imagem é um momento da história, mas também uma categoria interpretativa da história, uma perspectiva. Estamos aqui próximos de uma compreensão sobre as "formas" e a presença, entre o que se herda e o que se atualiza. A distância como capacidade de nos atingir, do choque, de rever-se com outros olhos, de estranhar-se. Tomamos o tempo, que é fundamentalmente aberto, como imensidade do futuro e do passado, configurando uma antropologia que parte dessa relação com o aberto com que temos contato quando, próximos da experiência vivida, encontramos a história tal como narrada.

Gostaria de nomear uma reflexão sobre o caráter narrativo da duração e sobre a ordenação narrativa dos diversos momentos da história. Inaugurando uma compreensão não apenas do sentido já dado e dos processos de criação de sentidos, mas dos sentidos em porvir. A configuração, isto é, as formas do enredo e a construção das personagens; e sua refiguração, ou seja, "a transformação da experiência viva sob o efeito da narração" são dois momentos a serem compreendidos. Colocando a experiência dos que entram em contato com a narrativa como atividade específica de recepção que é também reapropriação criadora.

Debates recentes na teoria antropológica trazem como problema a noção de "presente etnográfico" por sua abordagem sincrônica. Posicionando-me, acerca das relações entre antropologia e história, notamos as redes densas de múltiplas temporalidades que cortam cada instante vivido, narradas de distintas perspectivas.

Apresentar essas redes, tecendo seus fios, nos faz cartografar situações experimentadas com recursos que articulam movimentos no tempo, no exercício de produção de sentido dos sujeitos com os quais dialogamos. Talvez pudéssemos superar uma oposição entre uma abordagem sincrônica e outra diacrônica, notando como o 
filme presentifica imagens de outros tempos no agora da pesquisa etnográfica, e como esse encontro é denso e mobiliza, choca. Como espanta perceber que já não somos, notar nosso próprio processo de criação.

Podemos fazer do conhecimento, desse que produzimos em relações mediadas por processos de realização de filmes, uma forma de produção de presença capaz de criar reflexões que iluminem universos simbólicos em relação, que sustentam ações. O vídeo etnográfico, como forma de conhecimento, é também uma forma de produção de performances que configuram sujeitos, a sua linguagem tem um papel ativo na criação e na descrição de relações sociais. A pesquisa da linguagem suficiente para nomear o mundo, para apresentá-lo, participa da relação que se estabelece com as formas de narrar o mundo criadas pelos sujeitos que acompanhamos. Procurei aqui esboçar as relações de intersecção entre imagem, memória e presença, a partir da narrativa de experiências de pesquisa na realização de filmes etnográficos e da revisão de uma polêmica que estrutura um campo teórico, a partir da noção de duração como um modo de refletir sobre o tempo na antropologia.

\section{Referências}

BACHELARD, Gaston. 1994. Esboço de ritmanálise. São Paulo, Editora Ática.

BENJAMIN, Walter. 1990. Sobre o conceito de história. Obras escolhidas. São Paulo, Brasiliense.

1997.

Obras escolhidas. Magia e técnica, arte e política. São Paulo, Brasiliense, As Passagens. Belo Horizonte, EdUFMG, 2007.

BERGSON, Henri. 1934 [1896]. Matière et mémoire: essai sur la relation du corps à l'esprit. Paris, Librairie F. Alcan.

Paulo, Martins Fontes.

1990. Matéria e Memória: ensaio sobre a relação do corpo com o espírito. São 2006. Memória e Vida. Textos escolhidos. São Paulo, Martins Fontes.

BOSI, Ecléa. 1987. Memória e sociedade. Memórias de velhos. São Paulo, TA Queiroz/Edusp. 
BURAWOY, Michael. 2003. Revisits: An outline of a theory of reflexive ethnography. American Sociological Review 68 (5).

CHAUÍ, Marilena de S. 1987. "Os trabalhos da memória". In Bosi, E. Memória e sociedade. Memórias de velhos. São Paulo, TA Queiroz/Edusp.

CLIFFORD, James. A experiência etnográfica. Antropologia e literatura no século XX. Rio de Janeiro, EdUFRJ, 2008.

CRAWFORD, Peter I. 1992. Film as ethnography. University of Manchester Press.

DAS, Veena. 2012. Entre palavras e vidas: Um pensamento de encontro com margens, violências e sofrimentos. MisSe, Werneck, Birman, Pereira et ali. Entrevista com Veena Das. Dilemas. Vol. 5(2) :335-356.

DAWSEY, Jonh Cowart. 2005. O teatro dos "Bóias-Frias": repensando a Antropologia da Performance. Horizontes Antropológicos, ano 11, n. 24. Porto Alegre:15-34.

2006. Turner, Benjamin e Antropologia da Performance: O lugar olhado (e ouvido) das coisas. Campos 7(2): 17-25.

DELEUZE, Gilles. 1990. A imagem-tempo. São Paulo, Brasiliense.

1985. A imagem-movimento. São Paulo, Brasiliense.

1999. Bergsonismo. São Paulo, Editora 34.

DEVOS, Rafael Vitorino. 2006. Paisagens da narrativa oral: a descoberta da imagem. Cadernos de Antropologia e imagem. Rio de Janeiro, 23(2): 31-47.

DIDI-HUBERMAN, Georges. 1998. O que vemos, o que nos olha. São Paulo: Editora 34.

ECKERT, Cornelia e ROCHA, Ana Luiza Carvalho da. 2010. Cidade narrada, tempo vivido: estudos de etnografias da duração. Rua, 16(1). Campinas.

2009. Memória e ritmos temporais: o pluralismo coerente da duração no interior das dinâmicas da cultura urbano-contemporânea. Estudos históricos. 23(43), Rio de Janeiro, : 105-124.

2005. Imagens do tempo: por uma etnografia da duração. In: $O$ tempo e a cidade. Porto Alegre, Editora da UFRGS.

2000. Imagens do tempo nos meandros da memória: por uma etnografia da duração. In: Koury, Mauro G. P. (org.). Imagem e Memória: Estudos em Antropologia Visual. Rio de Janeiro, Garamond.

2000. A interioridade da experiência temporal do antropólogo como condição da produção etnográfica. Iluminuras 13. Porto Alegre, BIEV, PPGAS/UFRGS, 20pp.

EISENSTEIN, Sergei. 2002. A forma do filme. Rio de Janeiro, Zahar.

O sentido do filme. Rio de Janeiro, Zahar. 
FERRAZ, Ana Lucia Marques Camargo, Hikiji, Rose Satiko e Cunha, Edgar Teodoro da. 2006. O vídeo e o encontro etnográfico. Cadernos de campo 14/15:278-298.

FERRAZ, Ana Lucia Marques Camargo. 2009. Dramaturgias da autonomia. São Paulo: Perspectiva.

. 2009a. "No decorrer da luta, você vai se descobrindo": Experiências com o vídeo etnográfico na representação de processos sociais. Anthropológicas Ano 13, vol.20(1) :81-96.

, Barbosa, A. e Ferreira, F. 2009b. Fotografia e Memória: Entrevista com Miriam Moreira Leite. Anthropológicas. Ano 13, vol.20(1).

2010a. A experiência da duração no cinema de Jean Rouch. DocOnLine. Revista Digital de Cinema Documentário. 8-1. http://www.doc.ubi.pt/index08.html :190-211.

2010b. O drama de circo e o circo-teatro hoje. Uma experiência de representação de papéis com artistas circenses. Repertório. Vol. 13(15): 83-91.

FIESCHI, Jean-André. 1973. Dérives de la fiction. Notes sur le cinema de Jean Rouch. In Noguez, D. Cinéma, théories, lectures. Paris, Klincksieck,:109-114.

FLAHERTY, Robert. 1922. How I filmed Nanook of the North. The World's Work, XLIV:553560.

GAGNEBIN, Jeanne Marie. História e narração em Walter Benjamin. São Paulo, Perspectiva. . 2006. Lembrar esquecer escrever. São Paulo, Editora 34.

11(30), 1997. . Uma filosofia do cógito ferido: Paul Ricoeur. Revista Estudos Avançados

GROSSMAN, Alyssa. 2010. Choreographies of Memory: Everyday sites and practices of remembrance work in post-socialist, EU accession-era Bucharest. Thesis of PhD. Faculty of Humanities, University of Manchester.

GUERLAC, Suzanne. Thinking in time. Henri Bergson. Cornell University Press, 2006.

HEIDER, Karl G. Ethnographic film. Austin, University of Texas Press, 2006.

HENLEY, Paul. Seeing, hearing, feeling: sound and the despotismo of the eye in 'visual' anthropology. 2004.

IMBERT, Claude. 2003. “Warburg, de Kant à Boas”. L'Homme 165 :11-40.

LEFEBVRE, Henri. "Concepts, images, images-concepts". 
LEITE LOPES, José Sergio. A tecelagem dos conflitos de classe na cidade das chaminés. 1988. Brasília, EdUnB.

. 2011. "Memória e transformação social: Trabalhadores de cidades industriais". Mana $17(3):$ 583-606.

MACDOUGALL, David. 1994a. Whose Story Is It? In Ethnographic Film Aesthetics and Narrative Traditions, P. I. Crawford \& J. K. Simonsen, eds, Aarhus: Intervention Press, 1992: 25-42. Reprinted: Visualizing Theory, L. Taylor, ed., New York: Routledge, 1994: 27-36.

Routledge,: 260-70.

1994b. "Films of Memory" In Visualizing Theory, L.Taylor, ed., New York: Transcultural cinema. Princeton University Press, 1998.

University Press. The corporeal image. Film, ethnography and the senses. 2007. Princeton

MARESCA, Sylvain. 1996. La Photographie. Un mirroir des sciences sociales. Paris, L'Harmattan.

du Mirail.

1991. L'Autoportrait. Six agricultrices en quête d'image. Presses Universitaires

MARTINS, José de Souza, Eckert, Cornelia e Novaes, Sylvia Caiuby. 2005. O imaginário e o poético nas Ciências Sociais. Bauru, Edusc.

MENEZES, Ulpiano T. Bezerra de. 2003. "Fontes visuais, cultura visual, História visual. Balanço provisório, propostas cautelares" Revista Brasileira de História. São Paulo, v. 23, no 45, pp. 11-36.

MERLEAU-PONTY, Maurice. 2004. O olho e o espírito. São Paulo: Cosac \& Naify.

MOREIRA LEITE, Miriam Lifchitz. 2010. Roteiros imaginários. Florianópolis, Editora Mulheres.

Retratos de Família. São Paulo, Edusp.

NIETZSCHE, F. 1999. "Da utilidade e desvantagem da história para a vida". Considerações extemporâneas. (1873-1874). Col. Os pensadores. São Paulo, Nova Cultural. :273-287.

ORTEGA y GASSET, Jose. 1991. A idéia do teatro. São Paulo, Perspectiva.

PIAULT, Marc. 2000. Anthropologie et Cinéma. Passage à l'image, passage par l'image, Paris, Éd. Nathan.

PINHEIRO FILHO, Fernando A. 1996. A mente do todo: o encontro da sociologia durkheimiana com a questão do tempo. Dissertação de Mestrado em Sociologia, Universidade de São Paulo

PINK, Sarah 2001. Doing Visual Ethnography: images, media and representation in research London: Sage. 
Routledge.

2006. The Future of Visual Anthropology: engaging the senses, London,

RICOEUR, Paul. 1984. Temps et récit. Paris, Éditions du Seuil.

2000. La memoire, l'histoire, l'oublie. Paris, Éditions du Seuil.

ROUCH, Jean. 1976. "The camera and the man". Cine-ethnography. Feld, Stephen(ed.) Visible evidence 13. Minneapolis, University of Minnesota Press :29-46.

"La pyramide humaine" Cahiers du cinéma. 112. Paris :15-27.

. "On the vicissitudes of the self: the possessed dancer, the magician, the sorcerer, the filmmaker, and the ethnographer". 1978. SAVICO 5(1). Society for the Anthropology of Visual Communication.

RUBY, Jay. 1982. "Etnography as trompe l'oeil: Film and anthropology". A crack in the mirror. Reflexive perspectives in anthropology. University of Pensylvania Press, :121-131.

SAMAIN, Etienne. 2007."A matriz sensorial do pensamento humano. Subsídios para redesenhar uma epistemologia da comunicação. In Imagem, visibilidade e cultura midiática. Médola, A., Araujo, D. e Bruno, F.(orgs.). Porto Alegre, Sulina,: 63-79.

SARTRE, Jean Paul. 1981. A Imaginação. São Paulo, Hemus.

SCHUTZ, Alfred. 1979. Fenomenologia e relações sociais. Rio de Janeiro, Zahar.

SCHWARCZ, Lilia K. M. 2008. "Limites e fronteiras entre antropologia e história". Tese de Livre-Docência. FFLCH/USP.

SEVERI, Carlo. "A palavra emprestada ou como falam as imagens". Revista de Antropologia 52(2), 2009.

SILVA, Marcos Antônio da. 1986. O trabalho da linguagem. Revista Brasileira de História. São Paulo, v.6 n.11:45-61.

SJÖBERG, Johannes. 2006. "The ethnofiction in theory and practice". NAFA Network vol. 13(3).

2008. "Ethnofiction: drama as a creative research practice in ethnographic film”, Journal of Media Practice, Intellect Books \& Journals, Vol. 9 Issue 3, :229-242.

STOLLER, Paul. 1994. "Ethnographies as texts/ethnographers as gritos". American Ethnologist. 21(2):353-366. American Anthropological Association.

TURNER, Victor. 2005. "Dewey, Dilthey e Drama: um ensaio em antropologia da experiência". Cadernos de Campo 13. Universidade de São Paulo.

YATES, Frances A. 1966. The art of memory. Routledge \& Keagan Paul.

\section{Filmografia citada}


FERRAZ, Ana Lúcia. Feliz ano novo, véio! 1999.

. Foi através da necessidade. O Movimento por moradia em Osasco, SP. 2002.

Dramaturgias da Autonomia. 2005.

e Barbosa, Andrea M.M. e Ferreira, Francirosy. Caminhos da Memória. Miriam Moreira Leite. 2006. LISA/USP.

. A etnoficção e a pesquisa com Circo-Teatro. 2010.

Amores de Circo. 2009.

Cunha, E.T., Morgado, P. E Sztutman, R. Jean Rouch. Subvertendo fronteiras. 2000. LISA/USP.

FLAHERTY, Robert. O homem de Aran. 1934.

GROSSMAN, Alyssa. In the light of memory. 2010.

LEITE LOPES, José Sergio, Alvin, R. e Brandão, C. Tecido Memória. Museu Nacional/UFRJ, 2010.

ROUCH, Jean. Chronique d'un été. Paris, Argos Films, 1960.

Cocorico! Monsieur Poullet. Niger, 1974.

Folie ordinaire d'une fille de Cham. Paris, 1988.

La pyramide humaine (Costa do Marfim). Paris, Les Films de la Pléiade, 1961.

Petit a Petit. Paris, Les Films de la Pléiade. 1968 e 1972.

Recebido em:16/08/2013

Aprovado em: 20/08/2013 